\title{
PkM Pendampingan Pembentukan Modul Praktikum Embeded Kelistrikan Di Madrasah Aliyah Annida Al Islamy Jakarta
}

\author{
Meilia Nur Indah susanti ${ }^{1}$; Abdurrasyid ${ }^{2}$; Indrianto ${ }^{3}$; Herman Bedi Agtriadi ${ }^{4}$ \\ 1,2,3,4 Institut Teknologi PLN, \\ Prodi Teknik Informatika, Fakultas Telematika Energi \\ ${ }^{1}$ meilia@itpln.ac.id
}

\begin{abstract}
Annida Al-Islamy Islamic School Jakarta is one of the schools whose subjects have lessons on electronics, especially embedded systems. Embedded lessons become an important lesson because this lesson is a subject that opens the gates of students' minds so that literacy of technology and embedded systems can be used for the field of electricity.

Learning embedded without a laboratory then students just imagine with what is explained by the teacher about what is embedded system then the purpose of research here in general is to do assistance to the creation of embedded practicum module is expected students from Madrasah Aliyah Annida Al-Islamy Jakarta can understand and improve the results of learning about embedded system lessons, more especially electrical embedded system lessons. Based on the results of the analysis in the initial questionnaire that students' understanding of embedded systems without using modules obtained results of $58.8 \%$.

By doing assistance is expected to be used, especially in the school of electrical electronics laboratory at madrasah Aliyah Annida Al-Islamy jakarta. And after the mentoring of students by using the module the level of understanding becomes $80.1 \%$. So it is expected that this practicum module can be used for school progress to improve lessons on electronics especially in the field of electricity.
\end{abstract}

Keyword: Embedded system, Electrical, Annida Al-Islamy Islamic High School

\begin{abstract}
ABSTRAK
Sekolah Islam Annida Al-Islamy Jakarta merupakan salah satu sekolah yang mata pelajarannya terdapat pelajaran tentang elektronika terutama embedded system. Pelajaran embedded menjadi pelajaran yang penting dikarenakan pelajaran ini merupakan suatu mata pelajaran yang membuka gerbang pikiran siswa agar supaya melek akan teknologi dan embedded system dapat dimanfaatkan untuk bidang kelistrikkan.

Mempelajari embedded tanpa adanya laboratorium maka siswa hanya membayangkan saja dengan apa yang diterangkan oleh gurunya tentang apa itu embedded system maka dengan itu tujuan penelitian disini secara garis besar adalah melakukan pendampingan terhadap pembuatan modul praktikum embedded ini diharapkan siswa - siswa dari Madrasah Aliyah Annida Al-Islamy Jakarta dapat mengerti dan meningkatkan hasil belajar tentang pelajaran embedded system, lebih khususnya pelajaran embedded system kelistrikan. Berdasarkan hasil analisa pada kuesioner tahap awal bahwa pemahaman siswa terhadap embedded system tanpa menggunakan modul didapatkan hasil sebesar $58,8 \%$.

Dengan melakukan pendampingan diharapkan nantinya dapat dimanfaatkan terutama disekolah laboratorium elektronika kelistrikan pada sekolah Madrasah Aliyah Annida Al-Islamy jakarta. Dan setelah dilakukannya pendampingan siswa dengan menggunakan modul tingkat pemahaman menjadi $80,1 \%$. Sehingga diharapkan modul praktikum ini dapat dimanfaatkan untuk kemajuan sekolah untuk meningkatkan pelajaran tentang elektronika khusunya dibidang kelistrikan.
\end{abstract}

Kata kunci: embedded system, kelistrikan, Madrasah Aliyah Annida Al-Islamy 


\section{PENDAHULUAN}

Pendidikan sangatlah penting bagi kehidupan manusia untuk kehidupan di masyarakat dan berbangsa. Salah satu cita-cita bangsa Indonesia adalah memajukan Pendidikan bagi rakyatnya sehingga kegiatan pendidikan di Indonesia harus di organisasikan dan dikelola agar Pendidikan dapat menjadi sarana untuk mewujudkan cita-cita bangsa. Mengingat pentingnya peran Pendidikan sehingga pemerintah dalam meningkatkan kualitasnya dibutuhkannya proses pembelajaran[1][2]. Metode pembelajaran saat ini masih banyak yang dilakukan secara konvensional yaitu dengan metode ceramah atau hanya pemberian teori dan memberikan penugasan tanpa menggunakan modul. Sehingga peran guru dituntut harus aktif agar aktifitas belajar mengajar menjadi interaktif antara siswa dan guru[3].

Sekolah Madrasah Aliyah Annida Al Islamy Jakarta merupakan sebuah sekolah yang bernuansa islami dalam kurikulumnya dan juga merupakan sekolah berbasis agama Islam. Kalau berbicara masalah sekolah maka biasanya sekolah islam dikonotasikan sebagai sekolah yang mengajarkan dari sisi agamanya saja tetapi Sekolah Madrasah Aliyah Annida Al Islamy juga terdapat pelajaran elektronika tidak banyak sekolah yang mengajarkan pelajaran ini, mata pelajaran elektronika menjadi pelajaran yang penting dikarenakan pelajaran ini merupakan suatu mata pelajaran yang membuka gerbang pikiran siswa agar supaya melek akan teknologi. Pelajaran elektronika yang dimiliki oleh Sekolah Madrasah Aliyah Annida Al Islamy Jakarta masih bersifat konvensional. Yang artinya pelajaran yang dimiliki masih pelajaran yang mengadalkan teori tanpa dukungan laboratorium dan modul sehingga siswa hanya bisa membayangkan dari apa yang diajarkan saja.

Berdasarkan uraian tersebut maka disini diperlukannya pendampingan terhadap pelajaran elektronika dengan menggunakan modul yang dirancang sendiri diharapkan siswa - siswa dari Madrasah Aliyah Annida Al-Islamy jakarta dapat mengerti tentang pelajaran elektronika, lebih khususnya pelajaran tentang kelistrikan serta mengarah melakukan perbaikan perbaikan terhadap mata pelajaran yang ada pada Madrasah Aliyah Annida Al-Islamy Jakarta menjadi lebih baik.

\section{METODE}

Proses dalam penelitian ini menggunakan metode Research and Development (R\&D) dimana metode ini digunakan untuk penelitian yang menghasilkan produk tertentu serta menguji keefektifan produk tersebut [4]. Pendekatan ini dilakukan karena nantinya akan dihasilkan modul pratikum Embedded Kelistrikan[5] yang akan digunakan untuk siswa di Sekolah Madrasah Aliyah Annida Al Islamy Jakarta.

Ada 4 tahap proses pengembangan metode Research and Development (R\&D) yang nantinya dilakukan pada proses penelitian yaitu [6][7] 


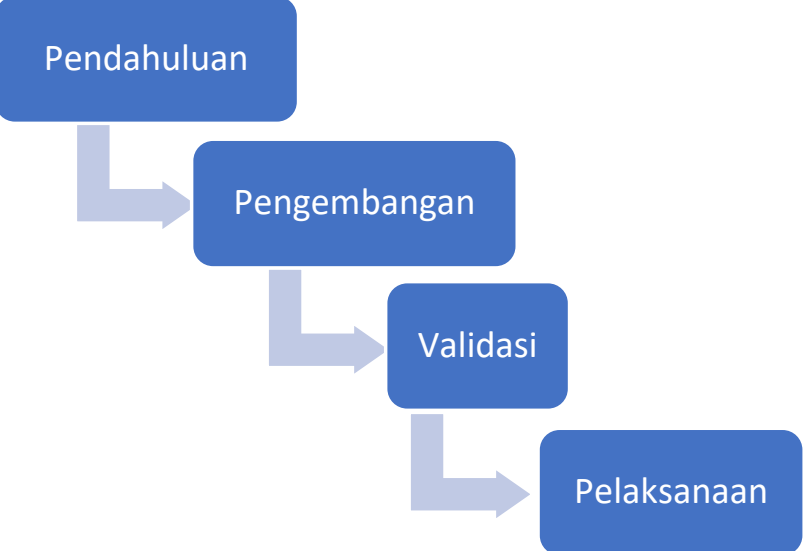

Gambar 1. Tahap Research and Development (R\&D)

Pada proses pendahuluan dilakukannya tahap siskronisasi modul praktikum embedded kelistrikan yang akan dibuat dengan silabus yang di miliki oleh pihak sekolah kemudian dilanjutkan pada tahap pengembangan modul praktikum embedded kelistrikan sesuai dengan yang diminta oleh pihak sekolah Madrasah Aliyah Annida Al Islamy Jakarta pada tahap validasi dimana dalam tahap ini akan melakukan proses konfigurasi ruangan agar sesuai dengan pratikum yang akan dikembangkan yaitu modul pratikum embedded kelistrikan, setelah proses pendahuluan sampai validasi selesai dilakukan maka akan dilakukannya proses pelaksanaan training kepada guru dengan maksud supaya guru yang mengajar dapat mengajarkan kembali matari yang akan diajarkan serta pemberian training kepada siswa dengan maksud supaya siswa tersebut mendapatkan sertifikat yang dapat digunakan untuk kelulusan. Durasi training dilakukan sebanyak 6 (enam) kali pertemuan dimana 3 (tiga) kali untuk training guru pendamping dan 3 (tiga) kali untuk training siswa dengan waktu training masing-masing perkegiatan sebanyak 4 jam.

Populasi didalam penelitian ini adalah siswa kelas XI-MIA Sekolah Madrasah Aliyah Annida Al Islamy Jakarta, metode pengumpulan data pada tahap awal yang diterapkan dalam penelitian ini dengan pemberian pretest yang berbentuk kuesioner dimana hasil dari pretest ini untuk mengetahui apakah pembelajaran embedded system tanpa modul dapat membuat siswa mengerti tentang materi tersebut. Setelah itu hasil kuesioner di Analisa menggunakan metode likert.

Teknik analisis penilaian hasil kuesioner dengan menggunakan kriteria presentase dimana meliputi: sangat kuat, kuat, cukup, lemah dan sangat lemah seperti gambar dibawah ini:

$$
\text { persentase }=\frac{\text { jumlah skor yang diperoleh }}{\text { total skor responden }} * 100 \%
$$

Table 1. Kriteria presentase penilaian Responden [3]

\begin{tabular}{|l|l|}
\hline \multicolumn{1}{|c|}{ Persentase } & \multicolumn{1}{c|}{ Kriteria } \\
\hline $0 \%-20 \%$ & Sangat lemah \\
\hline $21 \%-40 \%$ & Lemah \\
\hline $41 \%-60 \%$ & Cukup \\
\hline $61 \%-80 \%$ & Kuat \\
\hline $81 \%-100 \%$ & Sangat Kuat \\
\hline
\end{tabular}


Kriteria perentase dikatakan baik apabila $\geq 61 \%$ dan hasil analisis penilaian responden untuk pretest mendapatkan hasil 58,8\% dimana nilai tersebut masuk ke dalam kriteria Cukup, ini bearti masih adanya siswa yang masih belum memahami materi embedded system kelistrikan tanpa menggunakan modul. Tergambar pada grafik dibawah ini dari semua pertanyaan dari responden

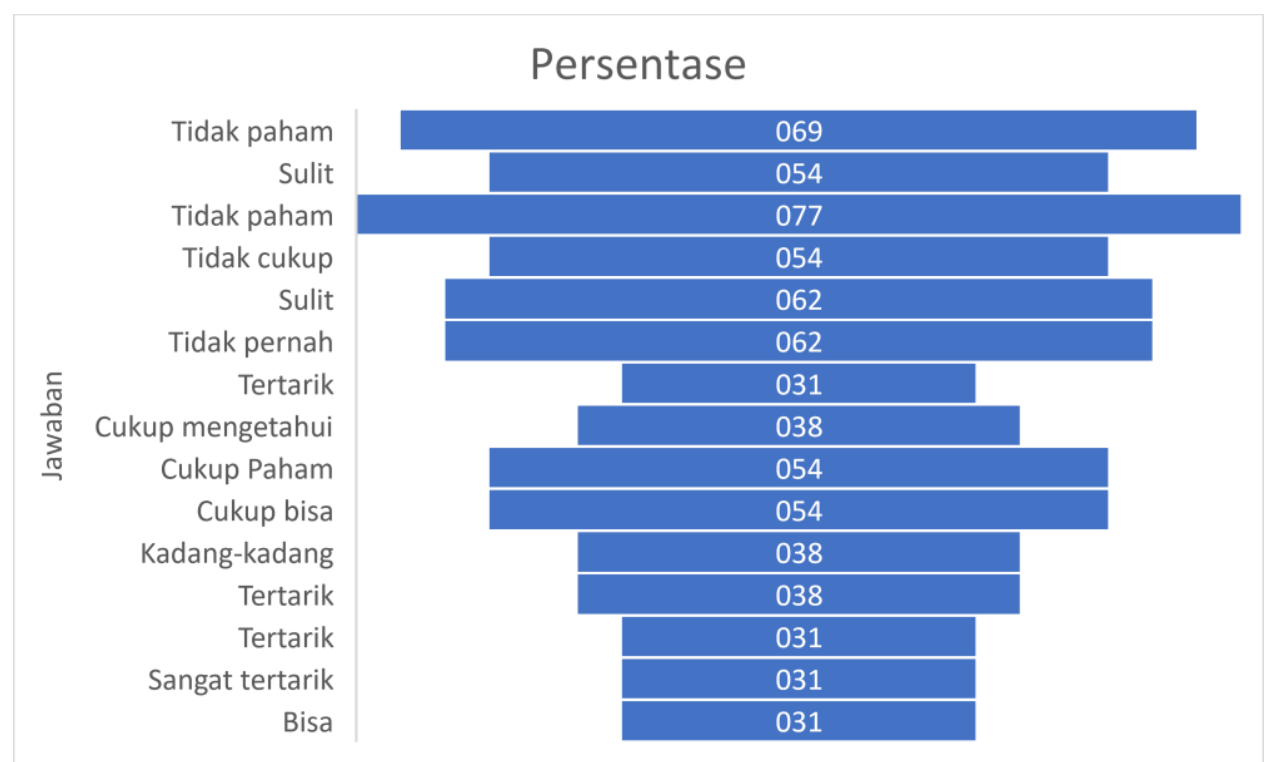

Gambar 2. Grafik jawaban pretest responden

\section{HASIL DAN PEMBAHASAN}

Proses pendampingan terhadap pelajaran elektronika dengan menggunakan modul yang dirancang sendiri untuk siswa Madrasah Aliyah Annida Al Islamy Jakarta mempunyai tujuan untuk meningkatkan pemahaman siswa serta mendorong siswa untuk berinovasi sehingga dapat tercipta peralatan berteknologi dengan menggunakan embedded system yang mengarah ke embedded system kelistrikan. Indikator pengukuran pemahaman siswa dengan memberikan kembali kuesioner postest setelah dilakukannya kegiatan pendampingan dengan indikasi tingkat pemahamanan dan tingkat ketertarikkan mempelajari embedded system yang mengarah ke embedded system kelistrikan.

Dari 15 butir pertanyaan yang diberikan kepada siswa dengan analisis pertanyaan tersebut dengan menggunakan metode skala likert maka didapat hasil rating nilai persentase postest sebesar 80,1\% dimana ini bearti tingkat pemahaman dan tingkat ketertarikkan siswa sangat kuat menurut tabel kriteria penilaian responden[3]. Tergambar dalam grafik dibawah ini setiap jawaban dari setiap responden menunjukkan kearah positif adanya perubahan setelah diadakan pendampingan pelajaran embedded system kelistrikan. 


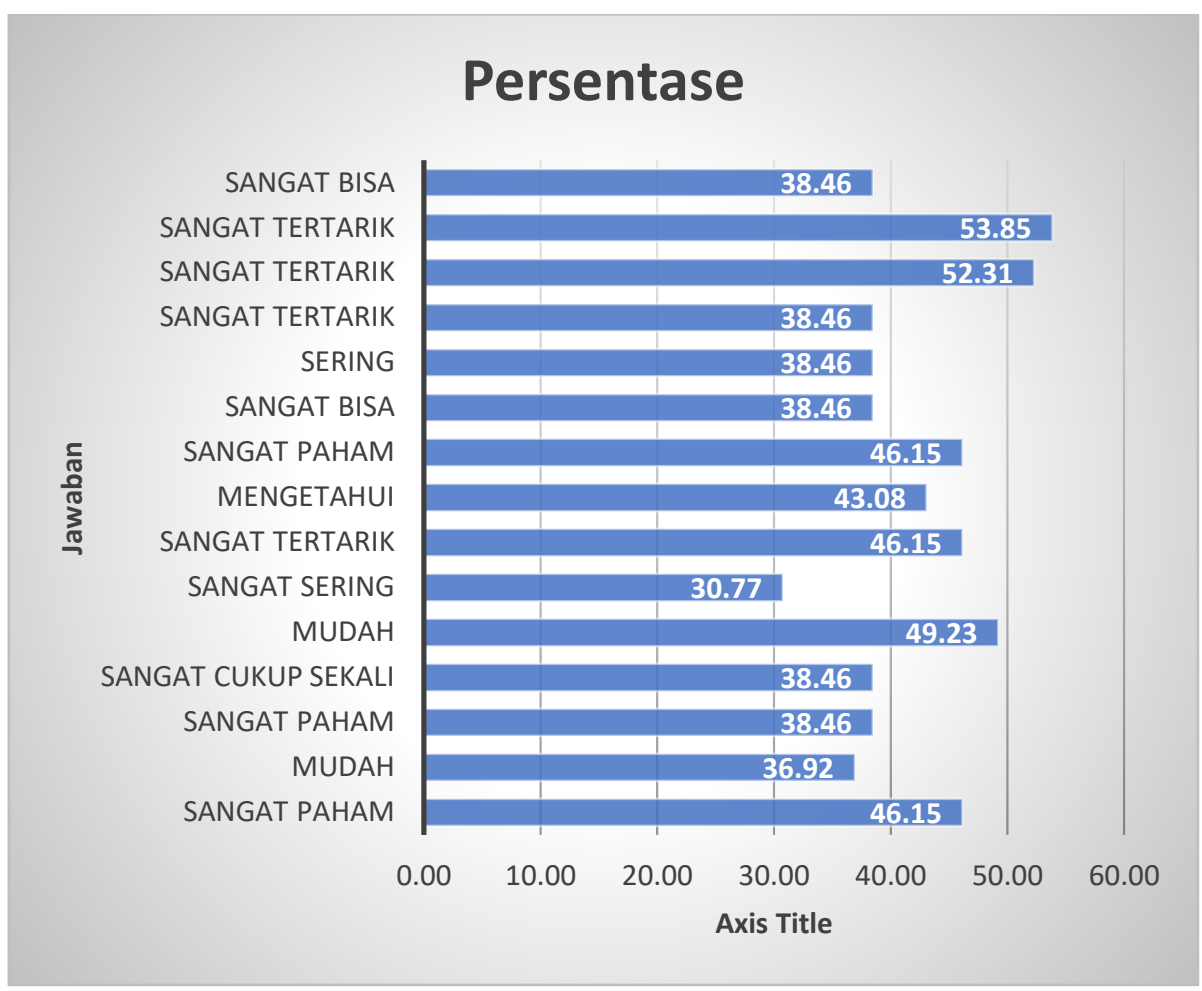

Gambar 3. Grafik jawaban postest responden

Untuk mengetahui adanya peningkatan setelah diadakan pendampingan berdasarkan hasil rating, maka perlu dilakukan Kembali perumusan hipotesis menggunakan uji $t$ terhadap data yang digunakan yaitu postest. Perumusan hipotesis disini melalui beberapa tahapan yaitu: (1) merumuskan hipotesis, $\mathrm{H}_{0}$ : terdapat peningkatan dan ketertarikan siswa terhadap pelajaran embedded system kelistrikan lebih besar $60 \%, \mathrm{H}_{1}$ : Tidak terdapat peningkatan dan ketertarikan siswa terhadap pelajaran embedded system kelistrikan lebih besar $60 \%$, melalui proses perumusan tersebut maka akan dilakukan pengujian satu pihak yaitu pihak kanan. (2) kriteria pengujian hipotesis satu pihak adalah $t_{\text {hitung }} \leq t_{\text {tabel }}$ jika kriteria tersebut memenuhi maka $H_{0}$ diterima sedangkan jika $t_{\text {hitung }} \geq t_{\text {tabel }}$ maka $\mathrm{H}_{0}$ ditolak.

Dengan diperolehnya nilai rata-rata hasil postest sebesar 27,53 dengan nilai standar deviasi 4,17 serta nilai rata-rata populasi sebesar 65 (skor ideal) dan menggunakan taraf signikan $(\alpha)$ sebesar $5 \%$ maka nilai $\mathrm{t}_{\text {hitung }}$ adalah:

$$
t_{\text {hitung }}=\frac{\bar{X}-\mu_{0}}{\frac{s}{\sqrt{n}}}=\frac{27,53-65}{\frac{4,17}{\sqrt{15}}}=\frac{-36,47}{1.08}=-34,78
$$

Keterangan [8]:

$$
\begin{aligned}
& \bar{X}=\text { Rata-rata sampel } \\
& \mu_{0}=\text { Rata-rata populasi } \\
& S=\text { Standar Deviasi } \\
& \text { I } n=\text { data } \\
& \mathrm{r} 1,76 \text { (pengujian uji satu pihak kanan) dengan } \quad \mathrm{df}= \\
& \mathrm{dk}-1 \text { yaitu } 15-1=14 \text {, maka dapat dbandingkan dengan kriteria } \mathrm{t}_{\text {hitung }} \leq \mathrm{t}_{\text {tabel }}=-34,78 \leq 1,76 \\
& \text { sehingga kesimpulan yang didapat adalah hipotesis terdapat peningkatan dan ketertarikan siswa }
\end{aligned}
$$


terhadap pelajaran embedded system kelistrikan lebih besar 60\% diterima sedangkan hipotesisi tidak terdapat peningkatan dan ketertarikan siswa terhadap pelajaran embedded system kelistrikan lebih besar $60 \%$ ditolak, tergambar dalam grafik dibawah ini:

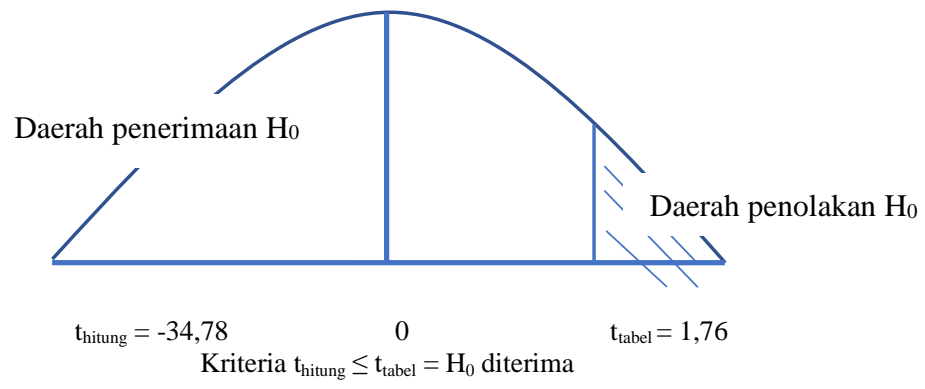

Gambar 4. Grafik pengujian hipotesis

Pendampingan yang dilakukan terhadap siswa Madrasah Aliyah Annida Al Islamy Jakarta dapat tergambar seperti dibawah ini.

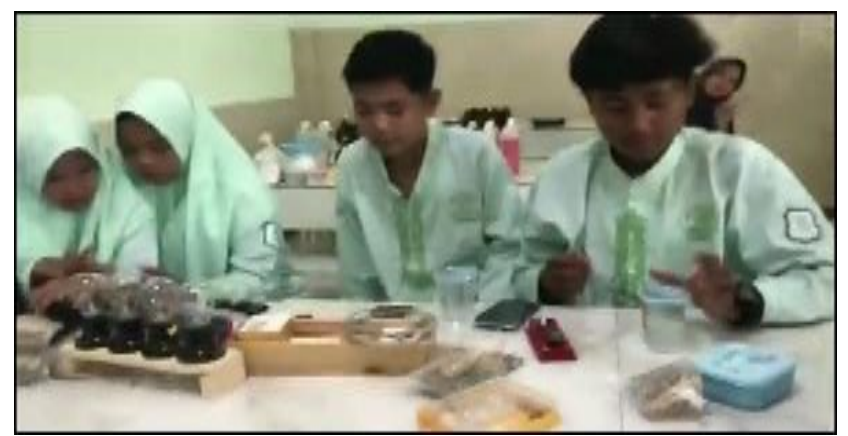

Gambar 5. pendampingan siswa madrasah Aliyah Al Islamy Jakarta

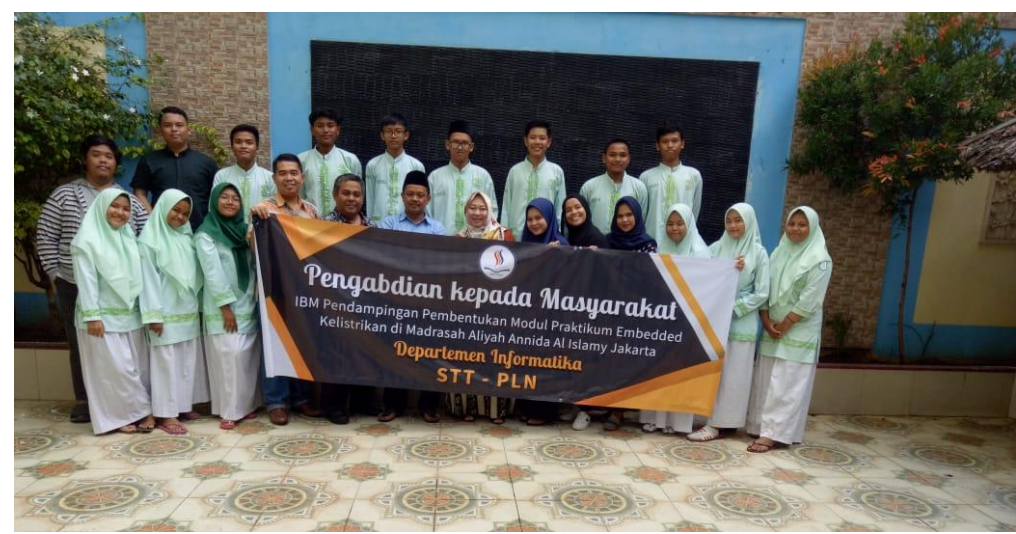

Gambar 6. Kegiatan setelah dilakukan PkM

\section{KESIMPULAN}

Berdasarkan hasil dari kegiatan pendampingan kepada siswa Madrasah Aliyah Annida Al Islamy Jakarta didapat kesimpulan: (1) hasil analisis postest menggunakan skala likert menunjukkan hasil positif dengan kriteria sangat kuat karena mendapatkan nilai diatas $80,1 \%$ dibandingkan pretest dengan nilai hanya $58,8 \%$ (2) hasil pengujian hipotesis dengan uji $t$ didapat peningkatan dan ketertarikan siswa terhadap pelajaran embedded system kelistrikan lebih besar dari $60 \%$ dengan hipotesis diterima. 


\section{SARAN}

Perlu dilakukan lagi kegiatan pelatihan berikutnya berkaitan tentang modul kelistrikan sehingga pengetahuan dan pemahaman siswa menjadi lebih lengkap.

\section{UCAPAN TERIMA KASIH}

Penulis mengucapkan terima kasih kepada Lembaga Penelitian dan Pengabdian Kepada Masyarakat Institut Teknologi PLN yang telah memberikan dukungan atas terlaksananya kegiatan ini melalui hibah internal.

\section{DAFTAR PUSTAKA}

[1] A. Supriatin and A. R. Nasution, "IMPLEMENTASI PENDIDIKAN MULTIKULTURAL DALAM PRAKTIK PENDIDIKAN DI INDONESIA,” Elem. J. Ilm. Pendidik. Dasar, 2017, doi: 10.32332/elementary.v3i1.785.

[2] C. Education and S. Across, GLOBAL EDUCATION DIGEST 2010 Comparing Education Statistics Across the World. 2010.

[3] T. Dianasari and T. Elektro, "PENGEMBANGAN MODUL PEMBELAJARAN BERBASIS PROYEK PADA MATA PELAJARAN INSTALASI PENERANGAN LISTRIK UNTUK MENGETAHUI PENINGKATAN HASIL BELAJAR SISWA KELAS XI TIPTL SMK NEGERI 7 SURABAYA Subuh Isnur H," 2015.

[4] S. Haryati, "Research and Development (R\&D) Sebagai Salah Satu Model Penelitian dalam Bidang Pendidikan,” Res. Dev. Sebagai Salah Satu Model Penelit. Dalam Bid. Pendidik., 2012.

[5] Indrianto, M. N. I. Susanti, and D. Karina, "RESLanjut: The learning media for improve students understanding in embedded systems," 2017, doi: 10.1063/1.4994450.

[6] B. H. Hall, J. Mairesse, and P. Mohnen, "Measuring the returns to R\&D," in Handbook of the Economics of Innovation, 2010.

[7] Q. Xie, "Research Design and Methods," in Technical and Vocational Education and Training, 2016.

[8] Meilia nur indah susanti, "Statistik Deskriptif dan Induktif", graha ilmu yogyakarta,2010 